\title{
Al-Based Foams as Permanent Cores in Al Castings: Effect of Surface Skin Thickness and Composition on Infiltration and Core-Shell Bonding
}

\author{
Sara Ferraris ${ }^{1, *(\mathbb{D}}$, Antonio Santostefano ${ }^{1}$, Antonio Barbato ${ }^{2}$, Roberto Molina ${ }^{3}$ and Graziano Ubertalli ${ }^{1} \mathbb{D}$ \\ 1 Department of Applied Science and Technology, Politecnico di Torino, Corso Duca degli Abruzzi 24, \\ 10129 Torino, TO, Italy; antonio.santostefano@polito.it (A.S.); graziano.ubertalli@polito.it (G.U.) \\ 2 DACA-I Powertrains Engineering Srl, Via Giuseppe Giacosa 38, 10125 Torino, TO, Italy; abarbato@daca-i.com \\ 3 Teksid Aluminum Srl, Via Umberto II, 10022 Carmagnola, TO, Italy; roberto.molina@teksid.com \\ * Correspondence: sara.ferraris@polito.it; Tel.: +39-0110905768
}

Citation: Ferraris, S.; Santostefano,

A.; Barbato, A.; Molina, R.; Ubertalli,

G. Al-Based Foams as Permanent

Cores in Al Castings: Effect of Surface Skin Thickness and Composition on Infiltration and Core-Shell Bonding. Metals 2021, 11, 1715. https:// doi.org/10.3390/met11111715

Academic Editor: João Pedro Oliveira

Received: 30 September 2021

Accepted: 25 October 2021

Published: 27 October 2021

Publisher's Note: MDPI stays neutral with regard to jurisdictional claims in published maps and institutional affiliations.

Copyright: (c) 2021 by the authors. Licensee MDPI, Basel, Switzerland. This article is an open access article distributed under the terms and conditions of the Creative Commons Attribution (CC BY) license (https:// creativecommons.org/licenses/by/ $4.0 /)$.

\begin{abstract}
An emerging and still poorly explored application of aluminum foams is their potential use as permanent cores (inserts) in the casting of aluminum alloys. In this context, Al-based foams can introduce a weight reduction, the obtainment of cavities, a strength increase, the ability to absorb impact energy and vibration, acoustic insulation ability, the possibility to simplify the technological processes (no removal/recycling of traditional sand cores), and finally, they can be fully recyclable. Cymat-type $\mathrm{Al}$ foams with thin outer skin were used as permanent cores in Al-alloy gravity casting in the present research. Al-foams were characterized in terms of porosity, density, cell wall and skin thickness, surface chemical composition and morphology, and compression resistance. Cast objects with foam inserts were characterized by means of optical microscopy. The preservation of up to $50 \%$ of the initial porosity was observed for foam inserts with higher density. Metallurgical bonding between the foam core and the cast metal was observed in some regions.
\end{abstract}

Keywords: aluminum foam; casting; foam core; porosity; metallurgical bonding

\section{Introduction}

In automotive applications, weight reduction, acoustic insulation, and crash absorption are crucial points for materials to be used.

The use of foams for the absorption of acoustic vibrations in trucks has been investigated [1], but mainly considering polymeric foams which can have some concerns related to fire and temperature resistance and recyclability.

Moreover, the aluminum realization of hollow structures has been investigated for weight reduction by using sand cores [2]. However, this approach requires complex process design and can often lead to critical conditions in term of resistance.

Aluminum foams have been investigated as promising materials to match weight saving and crash energy/vibrations absorption in automotive applications [3,4]

Aluminum foams have also been proposed in order to locally increase mechanical properties of hollow aluminum structures, with the advantage of also introducing crash energy absorption and acoustic insulation [5].

In this context, the use of Al-based metal foams as permanent cores in the casting of Al-alloy can give numerous advantages, such as weight reduction compared to dense components, the obtainment of cavities in cast objects, strength increase in terms of hollow or T-shaped sections, impact energy and vibration absorption, acoustic insulation, and the simplification of the technological processes (no removal/recycling of traditional sand cores) and recyclability, compared to traditional sand cores [6]. However, this application is still poorly explored in the scientific literature (just a few papers/year, fewer than 10 patents published on this topic) in contrast with the increasing research and publication related to metal foams (from 100 papers/year to 600 papers/year in the last 20 years) [6]. 
Some attempts to use $\mathrm{Al}$ foam cores in casting experiments have been reported in the literature [7-11] and all these papers highlight the presence of an external continuous skin as a crucial parameter to avoid the infiltration of molten metal in the foam core porosity during casting. Moreover, in the cited works, it is reported that partial melting of the core surface during the molten metal-core contact is a key point for metallurgical bonding.

The production of a cast object with a foam core is also described in some patents [12-15], evidencing the technological and industrial interest in this kind of application of metal foams.

In the present paper, Cymat-type Al-based foams with a thin outer skin were considered possible permanent cores in gravity casting experiments with an Al-Si-Cu-Mg alloy (EN AB-46400). The foam inserts, with different density and pore size, were characterized in terms of porosity, pore dimensions, wall and skin thickness, and compression resistance. The cast objects with the foam cores were analyzed by means of optical microscopy to determine residual porosity, core-shell bonding, and microstructure.

The main aim of the introduction of foam inserts in aluminum casting is the realization of functional cavities, able to reduce component weight and introduce functional properties such as energy and vibration absorption ability.

The results are compared with those previously obtained by the authors with Havel Metal Foam type Al-based foams with a thick outer skin. The key points driving porosity maintenance and core-shell bonding are critically discussed as well as possible improvements.

\section{Materials and Methods}

Cymat-type Al-based foams (Al alloy with SiC particles as stabilizing agent, Cymat Technologies Ltd., Mississauga, ON, Canada) were acquired in the form of rectangular panels and cut into the form of bars (transversal section: $22 \mathrm{~mm} \times 12.7 \mathrm{~mm}$ or $12 \mathrm{~mm}$, length $122 \mathrm{~mm}$ ) for casting experiments as well as of small rectangular samples for physical and chemical characterizations. In this configuration, a continuous thin surface skin was present only on the top and bottom surfaces of the samples but not on perpendicular sides.

Three foams with different densities (Figure 1) were used for both characterization and casting experiments.

The density of the foams was calculated from weight and volume measurements on three representative bar samples per foam type. The average porosity of the foams was obtained from these data. Moreover, a "metallographic porosity" was estimated from image analyses on the cross section of the foam samples to be compared with the one of the same foams after insertion in casting. For the evaluation of the "metallographic porosity", three samples for foam type, around $130 \mathrm{~mm}^{2}$ each, were embedded in dark-colored resin (methyl methacrylate base plus catalyst) and metallographically polished. The image of the samples was digitalized with a high-resolution scanner. The regions of interest of the digital images, excluding the resin, were improved in contrast and brightness, corrected from shot and dark noise, and the Image segmentation and Erode and dilate filter were applied. In all cases, the final binary images were compared with the initial ones to evaluate the goodness of the digital image processing. 

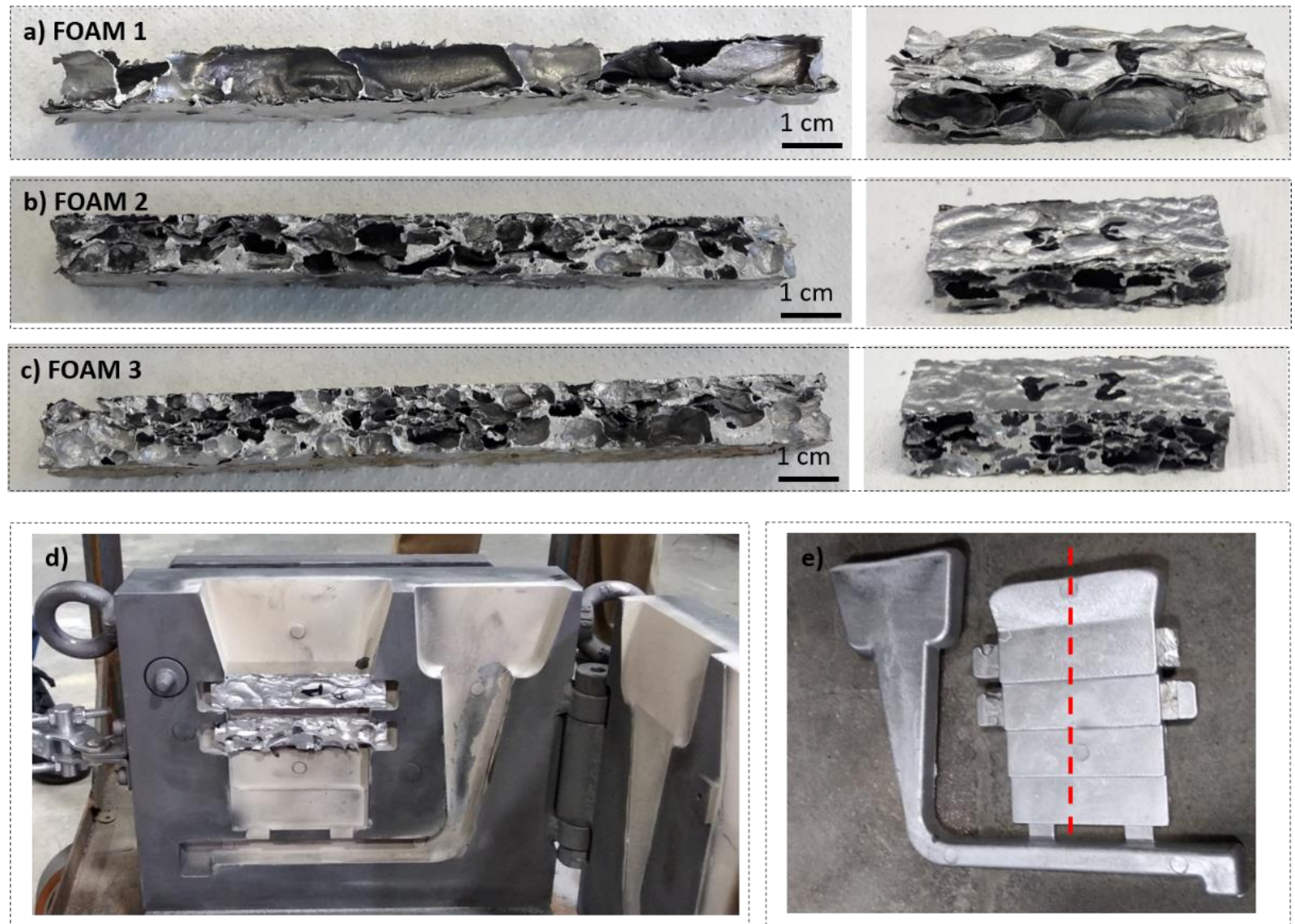

Figure 1. Cymat-type foam samples used in the experiments $(\mathbf{a}-\mathbf{c}),(\mathbf{d})$ gravity casting die with foam inserts, (e) cast object with foam inserts.

Small samples (1-2 cm side) were resin mounted and metallographically polished for optical and electronical microscopy analyses on the foam cross section.

The samples were observed by optical microscope (Reichert-Jung MeF3, Leica Microsystems Srl, Buccinasco (MI), Italy) in order to investigate the microstructure and to determine the pore dimensions, the thickness of the skin and of the pore walls by means of images processing by ImageJ software (Image J2 version, Fiji). The values of pore dimensions and skin and pore wall thickness were obtained from 50 measurements for each foam type. The measurement of pore size was obtained by the Feret's method, normally used for the measurement of the sizes of irregular shape particles.

The morphology and semi-quantitative chemical composition of Al-foams were investigated by means of Scanning Electron Microscopy equipped with Energy Dispersive Spectroscopy (SEM-EDS JEOL, JCM 6000 plus and JED 2300). The external surface of the foam samples was analyzed in the as-received and after washing conditions ( $5 \mathrm{~min}$ acetone in ultrasonic bath) or after grinding ( $\mathrm{SiC}$ paper 320 grit) and washing (as before) in order to investigate the surface features involved in the reaction with the molten metal in casting experiments.

Compression tests were performed on foam samples of $57 \mathrm{~mm} \times 20 \mathrm{~mm}$ (dimension of the rectangular top section) and a thickness, depending on the foam type, of $11 \mathrm{~mm}$ (foam 1) or $13 \mathrm{~mm}$ (foam 2 and 3). Samples of metal foams (not inserted in casting) were used for the mechanical characterization. The compressive force was applied on the rectangular top section (with thin continuous skin). The sample width was selected in order to be at least 7 times the mean pore size, as suggested in the scientific literature and in international standards [16-18] to avoid measurements artifacts. The test was performed with a speed of $1 \mathrm{~mm} / \mathrm{min}$ (according to [16-18], up to a $25 \mathrm{kN}$ maximum load). Three 
samples per foam type were tested. In order to take into account the differences in samples' thickness percentage, relative displacement, calculated as displacement/sample thickness, was reported in data comparison.

Foam bars samples, analogous to the ones previously characterized, were used as permanent cores in gravity casting experiments. A mold with stepped geometry, designed ad hoc for the experiment and shown in Figure 1d, was used for aluminum casting with the foam inserts. This stepped die foresees 2 steps (step 1-6 mm thick and step 2-11 mm thick) without foam inserts and two steps, with foam inserts (step 3 and step 4 with nominal thickness of the dense metal around the foam analogous to that of the steps 1 and 2 , respectively). The foam samples were positioned with the thinner cross-section (that without continuous skin) perpendicular in respect to the molten metal flow, as indicated in Figure $1 \mathrm{~d}$. The cast specimen containing foam 1 as core is denoted as S3, the one containing foam 2 as S1, and the one with foam 3 as $\mathrm{S} 4$.

The Al-Si-Cu-Mg alloy (EN AB-46400) was used in the casting experiments and an example of the obtained cast objects with foam inserts is shown in Figure 1e.

Cast products were longitudinally sectioned (following indicatively the red dotted line in Figure 1e) and visually observed in order to estimate the degree of infiltration of metal foam cores from the molten metal. Small samples of the different zones were collected, resin mounted, mirror polished, and analyzed at the optical microscope to investigate the residual porosity and the amount of the cast metal-foam core interface. Moreover, optical microscopy analyses $(100 \times$ magnification images) on small samples of the cast metal (without foam core) were used to calculate the Secondary Dendrites Arm Spacing (SDAS) by dividing the length of the principal dendrite by the number of secondary arms minus 1, as suggested in [19]. This parameter depends on the metal cooling rate and can be correlated with the mechanical properties of the cast object (microhardness, yield strength) [19-21].

Results obtained with the above-described types of foam were compared with the ones previously obtained using Al-based metal foams with a dense and thick outer skin (AF1; $\mathrm{Al}$ alloy with a limited amount of $\mathrm{TiH}_{2}$ as the foaming agent, Havel Metal Foams GmBH, Brandenburg an der Havel, Germany) [22,23].

\section{Results and Discussion}

The visual appearance of the Cymat-type foams, used in the present research, is shown in Figure 1. Foam 1 presents very big pores while smaller ones can be observed on foams 2 and 3 . All the foams show a high variability in pore size and shape and a very thin and irregular surface outer skin, as reported for Cymat type Al-based foams [6].

On the other hand, the Havel Metal Foam inserts, used in previous experiments [23], present smaller pores and a more homogeneous and thicker outer skin, as shown in Figure 2 for comparison.

For all the tested Cymat-type foams, the density, pore dimensions and outer skin and wall thickness are reported in Table 1 . The density of foam 1 was almost half of the one of foam 2 and 3 which were closer in value, confirming visual observation (Figure 1). Accordingly, the average porosity was higher for foam 1, compared to foam 2 and 3 . These differences were less evident when the metallographic porosity was calculated from optical microscopy images. This difference can be associated with the high variability in pore dimension and distribution which can more significantly affect these measurements and they are only performed on some metallographic sections. However, these values can be useful for a semi-quantitative evaluation of the infiltration degree when foam samples are used as permanent cores in casting experiments. The relative density of this type of foam is lower than the one reported for the HMF one (0.4-0.6) [22]. 

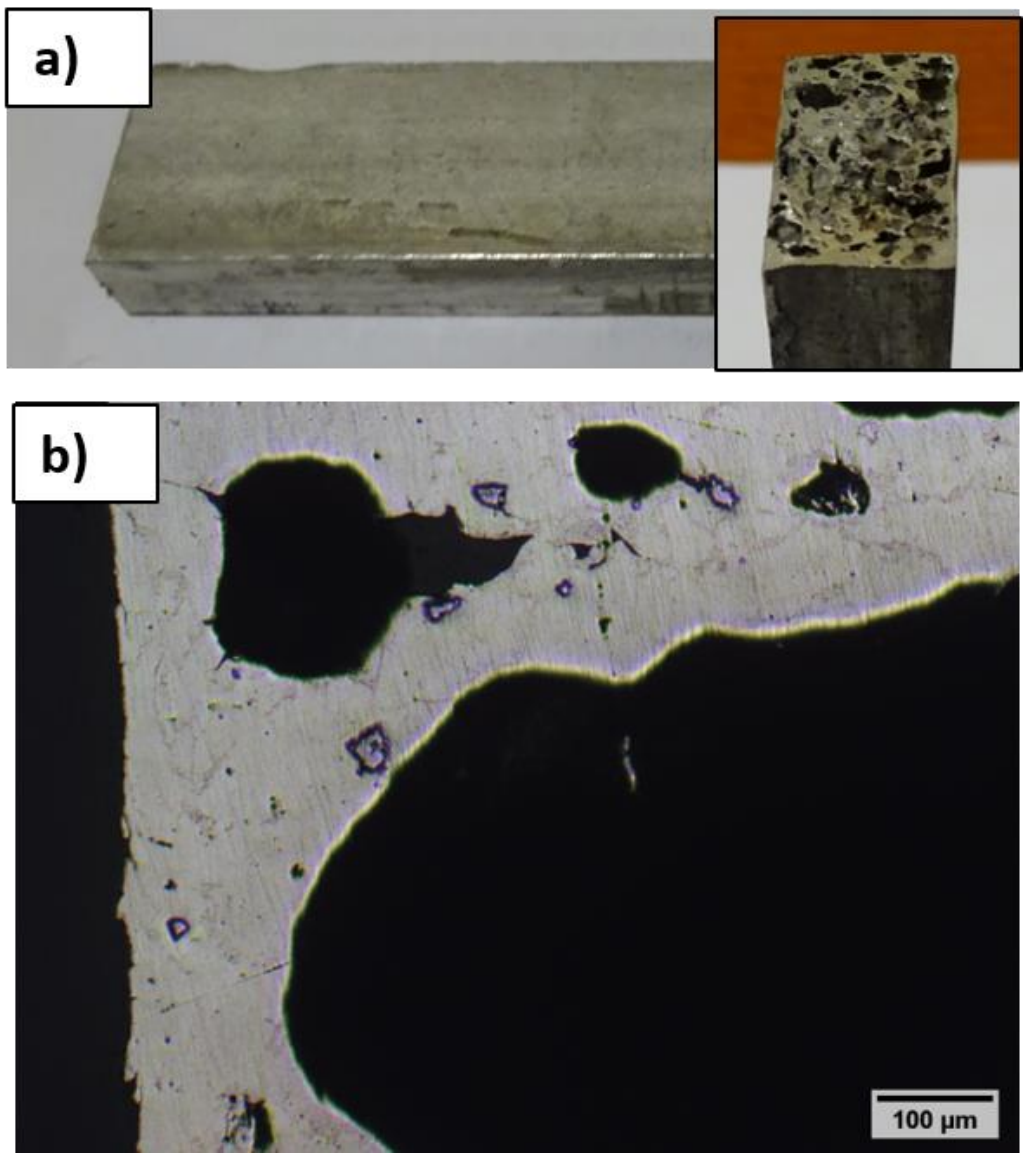

Figure 2. HMF foams, (a) visual appearance (top view and cross-section), (b) optical microscopy of the cross section $(100 \times$, no etching).

Table 1. Density, porosity, pore dimension, and skin and cell wall thickness of the Cymat-type foams.

\begin{tabular}{|c|c|c|c|}
\hline Parameter & Foam 1 & Foam 2 & Foam 3 \\
\hline$\rho\left(\mathrm{g} / \mathrm{cm}^{3}\right)$ & $0.29 \pm 0.04$ & $0.45 \pm 0.02$ & $0.56 \pm 0.04$ \\
\hline$\rho_{\mathrm{s}}$ (relative density) * & $0.11 \pm 0.01$ & $0.17 \pm 0.01$ & $0.21 \pm 0.01$ \\
\hline Average Porosity $\left(1-\rho_{s}\right)(\%)$ & 89 & 83 & 79 \\
\hline Metallographic porosity & 76 & 74 & 75 \\
\hline \multicolumn{4}{|l|}{ Pore dimension (mm) } \\
\hline Mean & 8.15 & 4.22 & 3.10 \\
\hline Min & 1.02 & 0.71 & 0.60 \\
\hline $\operatorname{Max}$ & 21.35 & 10.26 & 10.42 \\
\hline \multicolumn{4}{|l|}{ Wall thickness $(\mu \mathrm{m})$} \\
\hline Mean & 251 & 161 & 236 \\
\hline Min & 47 & 49 & 44 \\
\hline $\operatorname{Max}$ & 977 & 858 & 758 \\
\hline \multicolumn{4}{|l|}{ Skin Thickness $(\mu \mathrm{m})$} \\
\hline Mean & 201 & 130 & 162 \\
\hline Min & 54 & 57 & 55 \\
\hline $\operatorname{Max}$ & 671 & 315 & 305 \\
\hline
\end{tabular}

* Calculated considering the density of compact aluminum $\left(2.7 \mathrm{~g} / \mathrm{cm}^{3}\right)$ as reference.

Pore dimensions showed doubled values for foam 1 and more similar values for foams 2 and 3 according again with visual inspection (Figure 1). Pore dimension showed a high 
variability which can be correlated with the foam production process (direct gas injection in the molten metal) which leads to the development of a stochastic structure [24].

Cell walls and outer skin thickness were similar in thickness $(100-200 \mu \mathrm{m})$, as can also be observed from Figure 3 (first row). Both parameters presented a very low variability in their minimum values among the different foams, while the maximum values were always higher for foam 1 . In all cases, a high dispersion between the minimum and the maximum values could be observed. In comparison, a significantly thicker outer skin was measured for HMF foams (up to $1200 \mu \mathrm{m}$ ) [22,23].
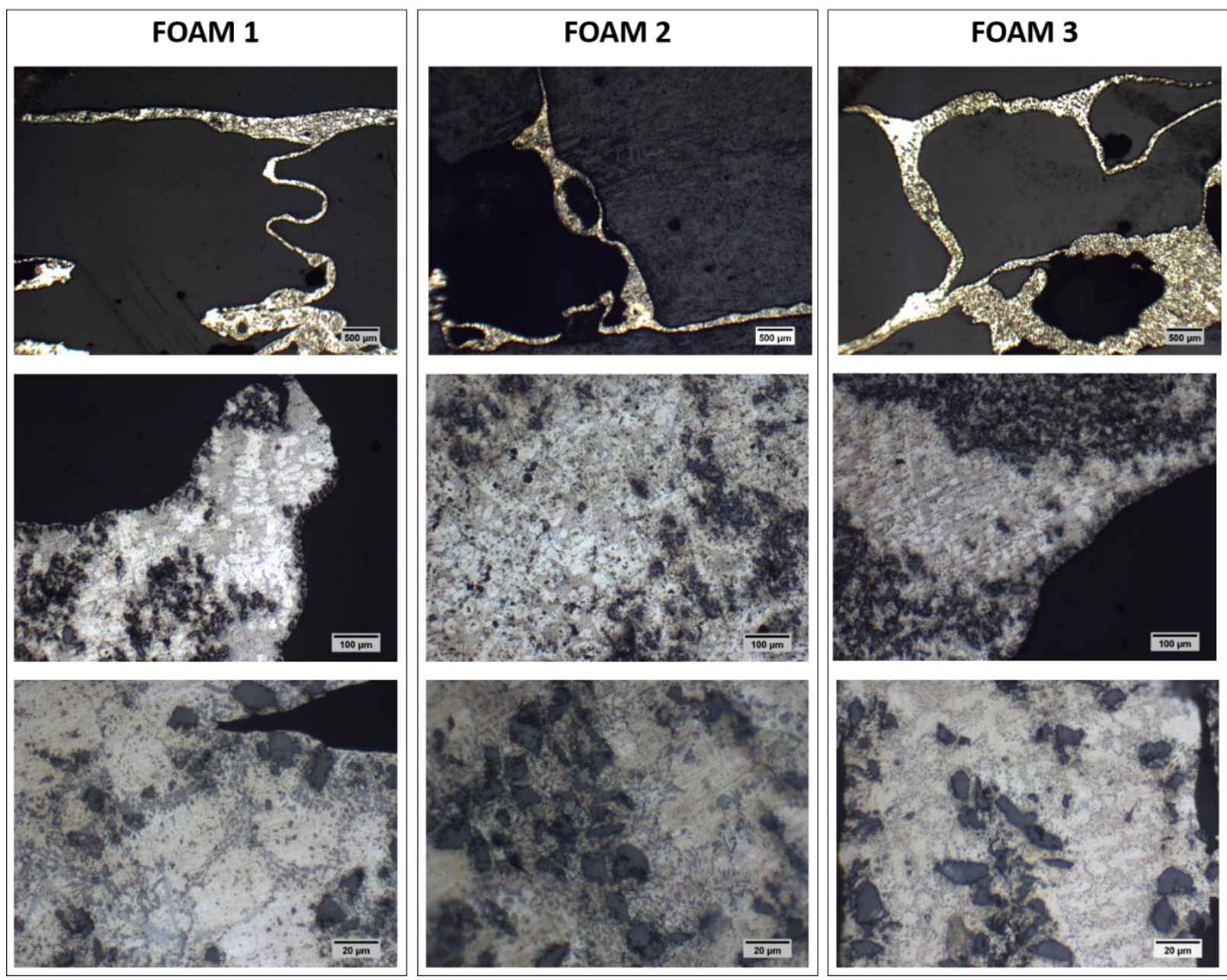

Figure 3. Optical microscope images of the foams cross-sections at different magnifications $(20 \times$ first row, $100 \times$ second row and $500 \times$ third row).

Optical microscope images of the foams' cross sections, at $100 \times$ and $500 \times$ magnifications, are reported in Figure 3 (second and third rows, respectively). The lighter areas can be ascribed to $\alpha$-phase (rich in $\mathrm{Al}$ ) with dendritic structure which is surrounded by light gray zones attributable to the Al-Si eutectic structure. Moreover, a high amount of dark gray particles could be observed, mainly at the surface. They could be SiC particles, frequently used to increase the molten metal viscosity in Cymat type $\mathrm{Al}$ foam production [6,25-28].

The different composition and production route of these foams result in a different microstructure compared to the HMF one (See Figure 2b for comparison). As reported in [23], HMF foams present Ti-rich particles associated with the powder metallurgy technology, which uses $\mathrm{TiH}_{2}$ as foaming agent and no stabilizing additives ( $\mathrm{SiC}$ ).

Semi-quantitative chemical composition of the foams was determined by EDS analyses on different areas of the foam cross section and reported in the bar graph of Figure 4a. The 
main elements detected on the foams were $\mathrm{Al}$ (the main constituent of the base metal), $\mathrm{Si}$ (which can be present as alloying element or as silicon carbide, the stabilizing agent), and oxygen (attributable to oxidation). Carbon could be associated to the presence of silicon carbide and minimally to surface contamination.
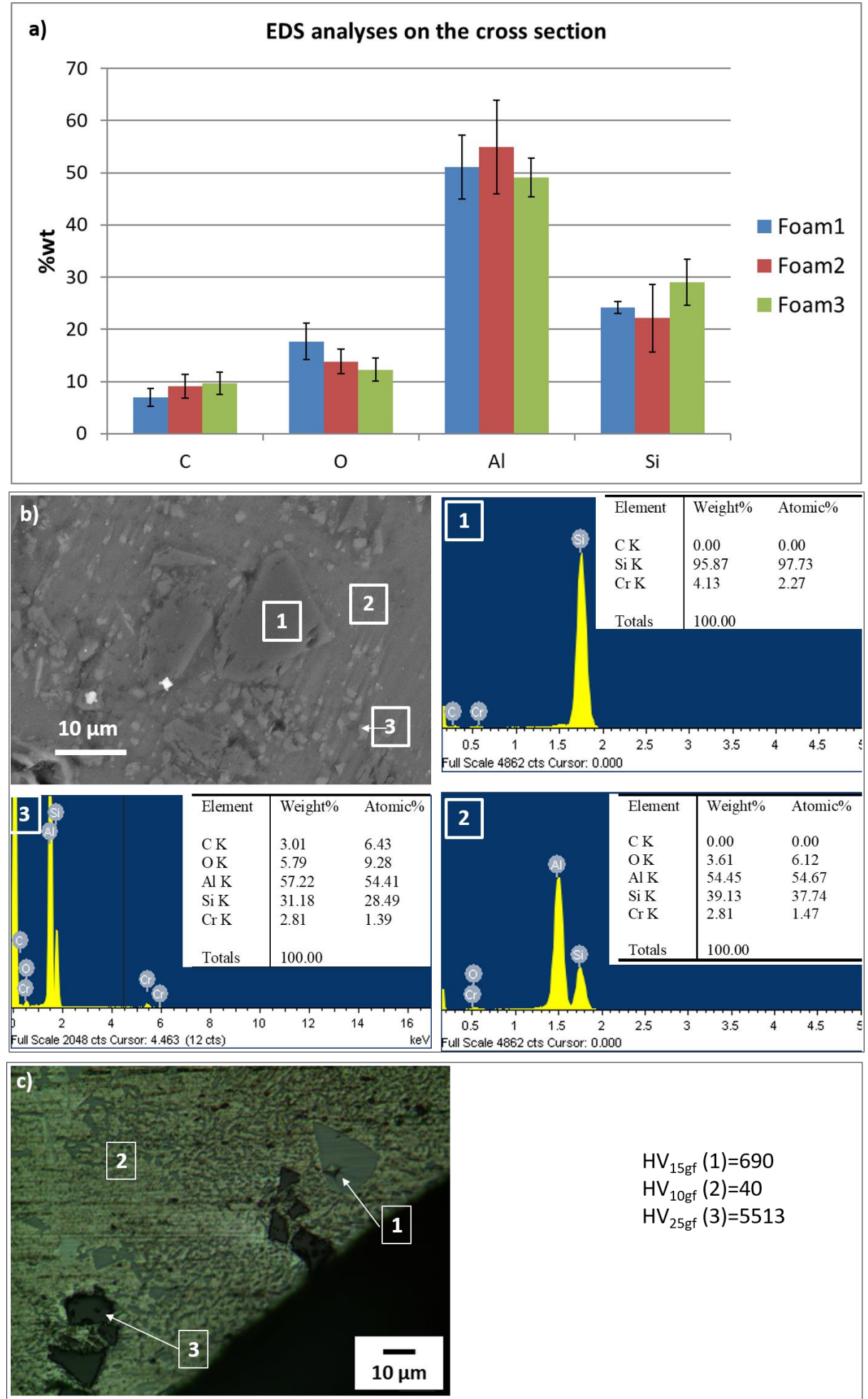

$H \mathrm{~V}_{15 \mathrm{gf}}(1)=690$

$\mathrm{HV}_{10 \mathrm{gf}}(2)=40$

$\mathrm{HV}_{25 \mathrm{gf}}(3)=5513$

Figure 4. SEM-EDS analyses (a) on the cross section of the different foams; (b) on localized regions of the cross section; and (c) micro-hardness measurements in selected points. 
SEM observations and localized EDS analyses on second phases particles and base metal are reported in Figure $4 \mathrm{~b}$. It can be observed that the base metal (EDS 2) was mainly constituted by $\mathrm{Al}$ and $\mathrm{Si}$, as expected and as previously reported for the whole cross section, with minimal oxidation. Cr can be referred to surface metallization of resin mounted samples. EDS analyses on the "second phases particles" evidenced two different typologies: EDS 1 (bigger particles) reports only Si while EDS 3 (smaller particles) showed both $\mathrm{Si}$ and $\mathrm{C}$ as main elements. These observations suggest the presence of both $\mathrm{Si}$ and $\mathrm{SiC}$ particles. Micro-hardness measurements (Figure 4c) confirm this hypothesis: the smaller particles had the highest hardness and could reasonably be $\mathrm{SiC}$ particles, the bigger ones had an intermediate hardness and could be Si particles while the base metal presented the lower HV value.

EDS analyses were performed also on the external surface of the foams samples as received and after washing or grinding and washing in order to better understand the surface reactions with molten metal in casting experiments, as previously reported for HMF foams [23]. Results are reported (for foam 3, as example) in the bar graph of Figure 5a. The surface skin of the as-received foams was mainly constituted of $\mathrm{Al}$ and $\mathrm{Si}$, similarly to the cross section, with limited amounts of $\mathrm{O}$ and $\mathrm{C}$ attributable to oxides and contaminations or $\mathrm{SiC}$, respectively. The SEM image of Figure $5 \mathrm{~b}$ confirms the presence of small oxide deposits (evidenced by box 1 with EDS analysis which shows high oxygen content compared to the base metal, box 2). Washing reduces both the carbon and oxygen amounts evidencing that some contaminations and oxides are weakly bonded to the surface and can be easily removed. On the other hand, only mechanical polishing would have allowed removal of magnesium oxides and carbonates, abundantly detected on the surface of HMF foams [23].
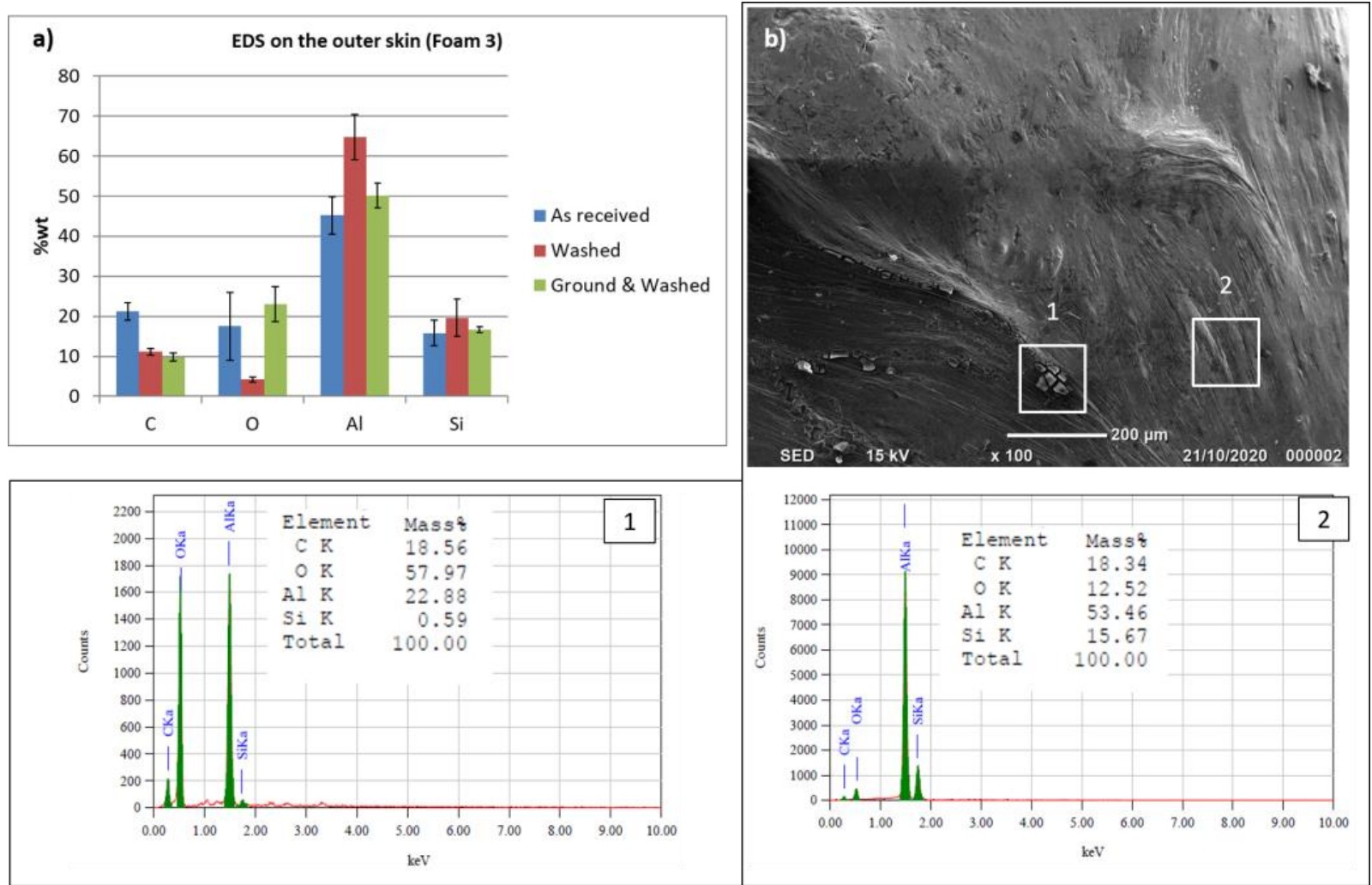

Figure 5. (a) EDS analyses on the outer skin of foam 3 (as example) after different surface preparations (as received, washed, ground and washed), (b) SEM-EDS analyses on specific point of the outer skin of the foam.

The results of compression tests are shown in Figure 6. Measurements were performed on 3 samples per foam type and, since the results obtained on each foam type were quite similar, one single curve for each foam was reported, for better readability. 


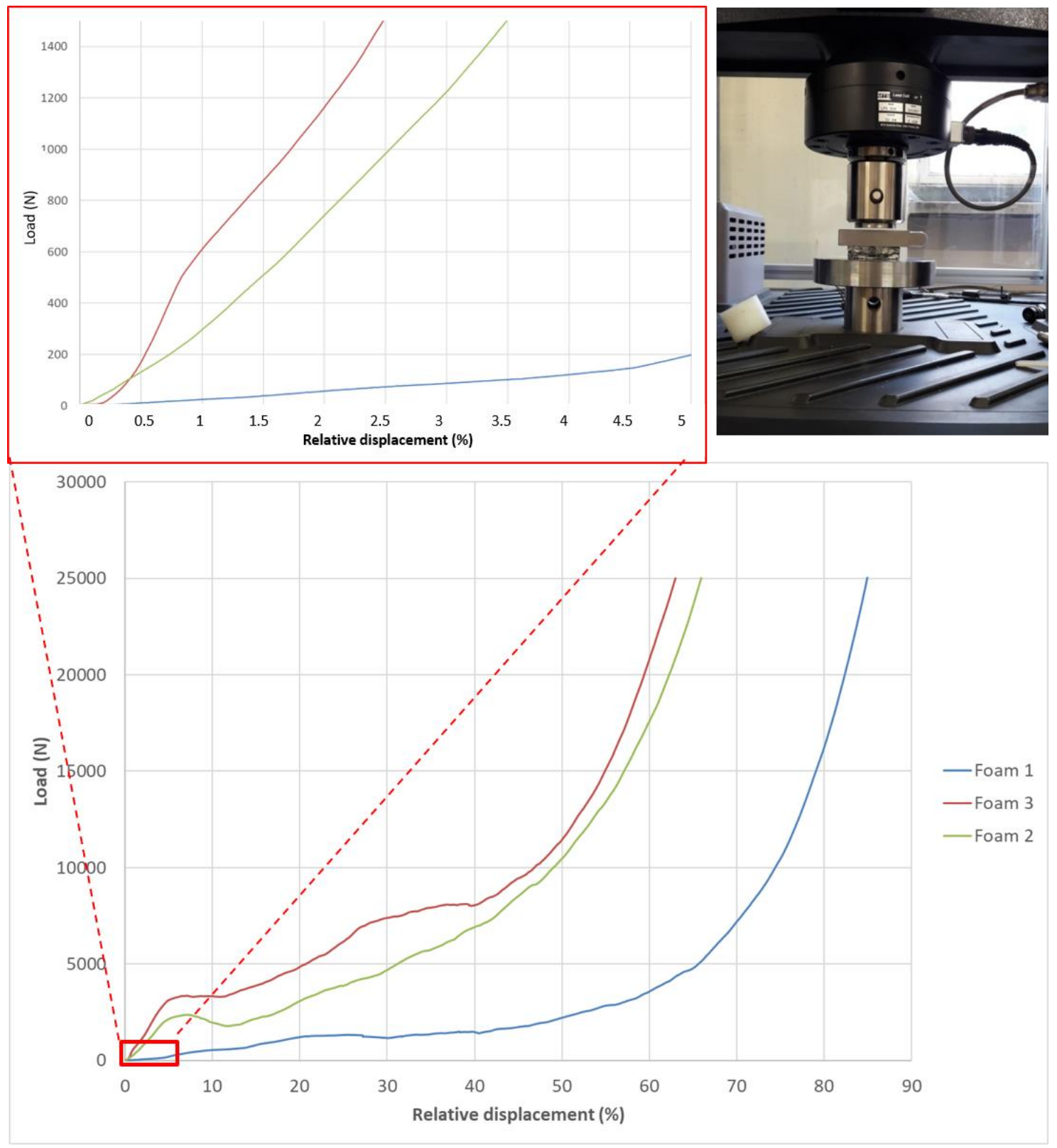

Figure 6. Compression test results of the different foams.

All the curves evidenced three main zones, as typically for compression tests of metal foams [29,30]. A first zone showed a linear behavior, until around $5 \%$ of relative displacement, associated with structure elastic deformation. This zone ended at low loads (less than $200 \mathrm{~N}$ for foam 1, about $1500 \mathrm{~N}$ for foam 2, and around $4000 \mathrm{~N}$ for foam 3). A second zone with evident plastic deformations, at around constant load, showed a plateau typical for metal foams and it was associated with their energy absorption ability [29,30]. The sample thickness reduction, in the direction of the compressive force applied, could reach values up to $50 \%$ of the total thickness in this zone (e.g., for foam 1). The load increase in this second step was negligible in case of the foam 1 while it showed a slight increase in the case of foam 2 and 3. In this zone, the porous structure of the cell walls plastically deformed because the localized material resistance was exceeded. The final zone showed a sudden increase of the required load with moderate increase in the relative displacement percentage, compared to the previous zones, and it was associated with the final densification. 
Compression tests evidenced a similar behavior for foams 2 and 3, with relative compression value around $20 \%$ and $30 \%$, respectively, at $5000 \mathrm{~N}$ load. On the other hand, foam 1 , at the same load $(5000 \mathrm{~N})$ presented a relative compression value of $65 \%$ and this load slightly exceeded the limit for constant load deformations. It could be observed that the compaction of the foams 2 and 3 was almost complete at around $50 \%$ of the relative displacement while that of foam 1 reached the value of $65 \%$. This means that the effect of porosity was particularly evident in elastic and plastic regions of the curve, while, after pore collapse, the foams behavior became more similar, as well as the load required for the final compaction.

The visual appearance (top view and cross section) and the optical microscope images of cast objects with the different foams as inserts are shown in Figures 7-9.
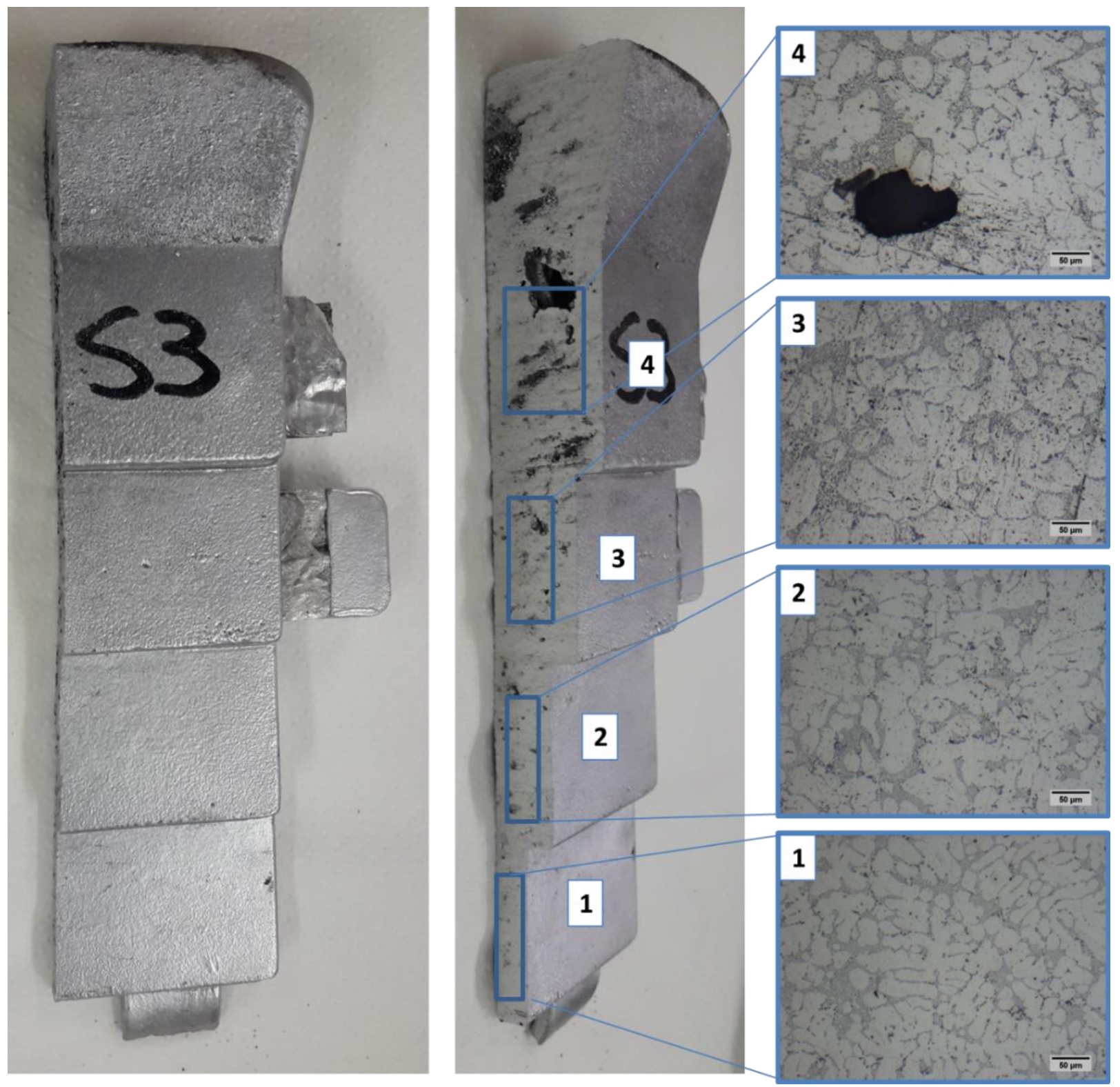

Figure 7. Foam 1 inserted in cast object, visual appearance of the cast object (top surface and cross section), and optical microscopy on the cross section. 1-4 optical images of the different steps of the cast object. 

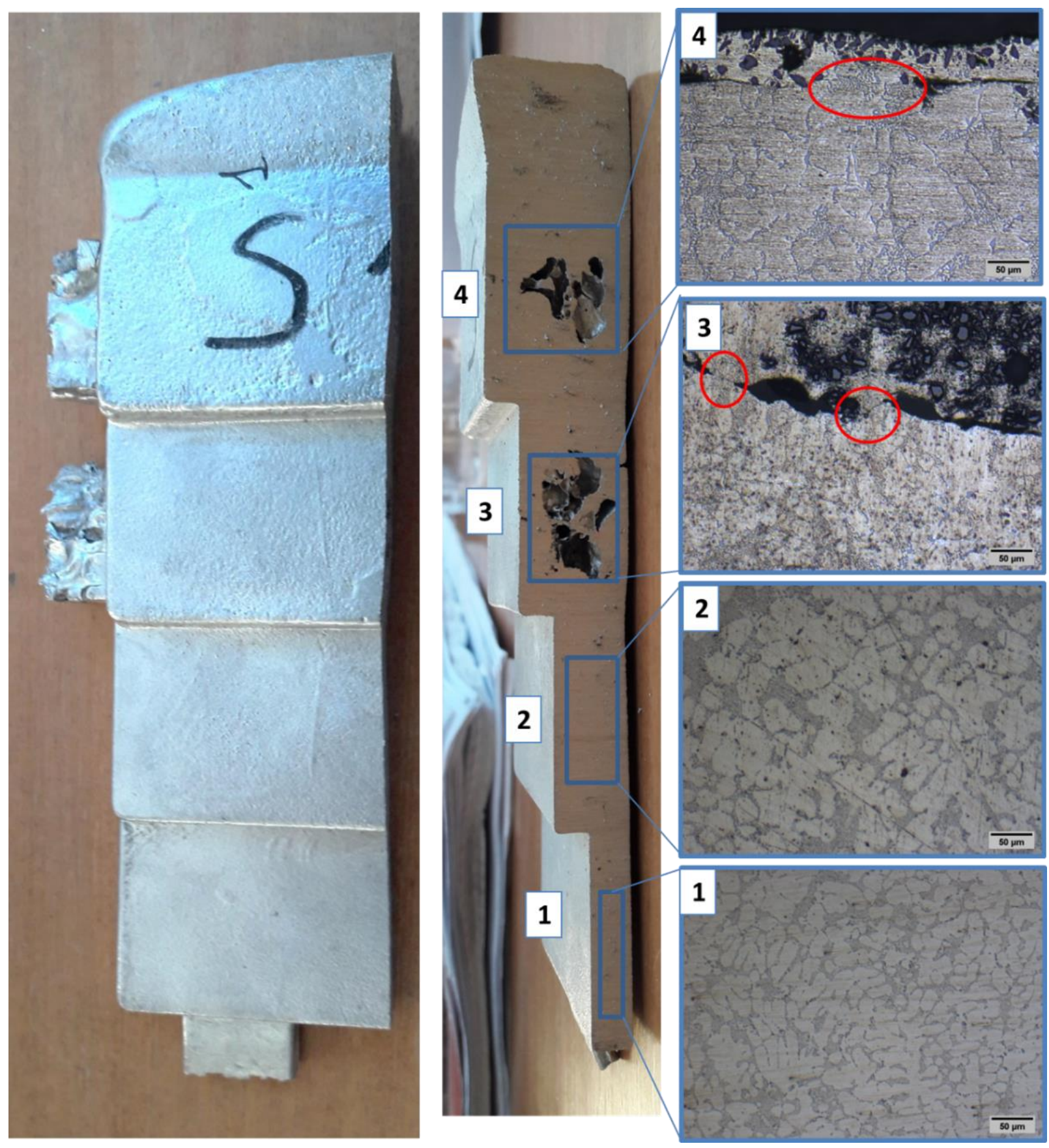

Figure 8. Foam 2 inserted in cast object, visual appearance of the cast object (top surface and cross section), and optical microscopy on the cross section. 1-4 optical images of the different steps of the cast object. 

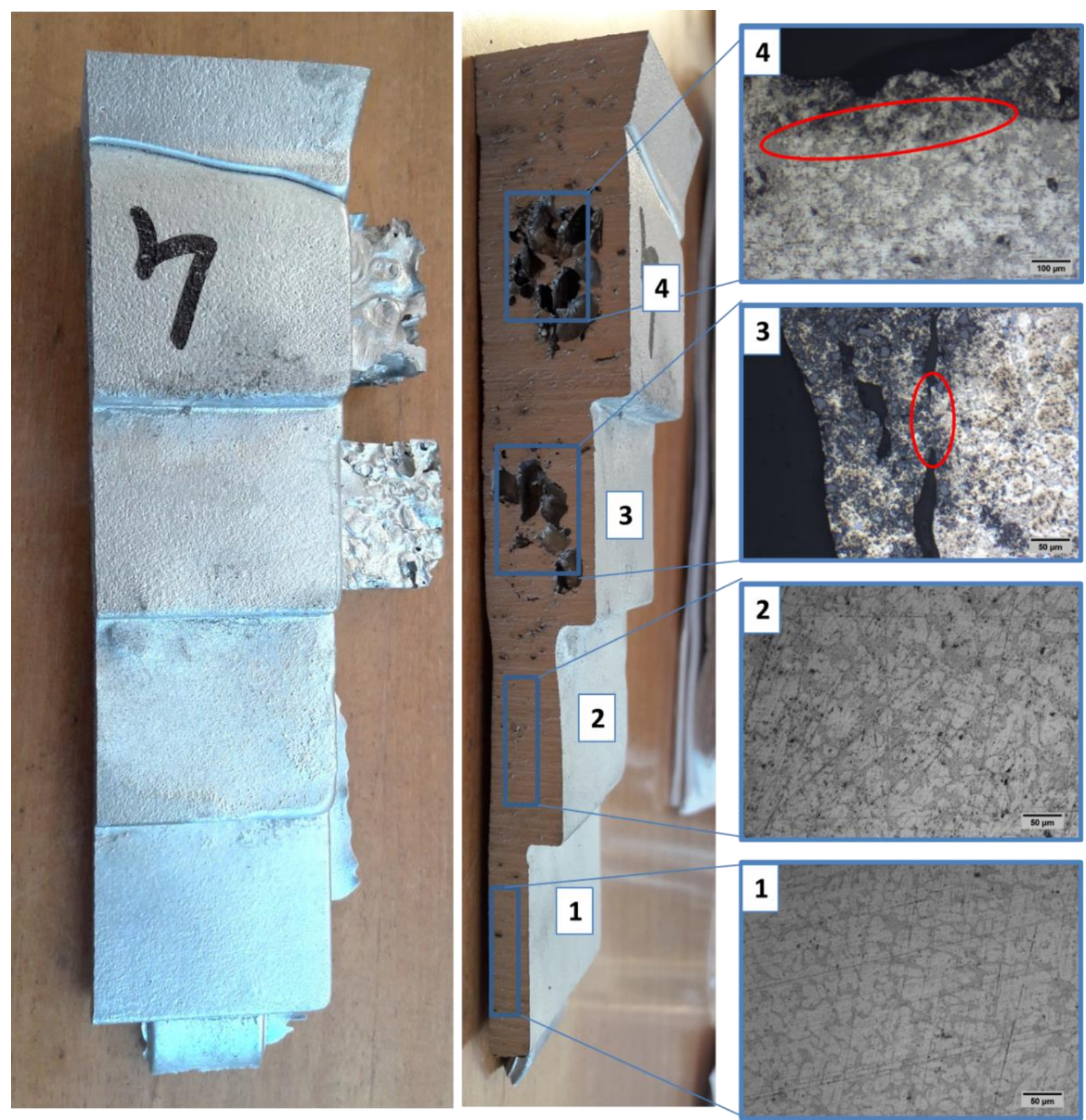

Figure 9. Foam 3 inserted in cast object, visual appearance of the cast object (top surface and cross section), and optical microscopy on the cross section. 1-4 optical images of the different steps of the cast object.

When foam 1 was used as insert, almost complete infiltration from the molten metal occurred (Figure 7). This phenomenon can be associated with the large open pores on the cross section which received the molten metal flow and with a thin outer skin on the lateral sides which, in presence of big porosities, is not able to resist to molten metal infiltration.

On the other hand, a certain amount of porosity was maintained in the case of foams 2 and 3 as inserts: $30-40 \%$ for S1 sample (Figure 8 ) and at about $40 \%$ for S4 sample (Figure 9), considering a transversal cross-section. Considering that, before insertion in casting the metallographic porosity was around $75 \%$ for these foams (Table 1), it can be concluded that at about half of the foam porosity is maintained after their use as permanent cores in casting.

In contrast, no infiltration was observed using HMF foams, with thick outer skin as inserts $[22,23]$. These results confirm that the presence of a thick and continuous outer skin 
can effectively preserve foam cores from infiltration by molten metal, as reported in the literature [7-9].

Looking at the optical microscope images, it can be observed that the cast Al-alloy presented a typical dendritic microstructure with an Al-rich phase (the lighter one, $\alpha$-phase) surrounded by a eutectic Al-Si structure, in the dense metal zone of steps 1 and 2 (without foam inserts) and around foam inserts in step 3 and 4 zones.

In Figures 8 and 9, the interface between the foam inserts and the cast metal can be observed in steps 3 and 4 . A certain gap (few microns) can be noticed in some points, in other areas (evidenced by red ovals), even if a metallurgical continuity can be observed between the two structure, evidencing a certain degree of bonding. The microstructural continuity, with occasionally transfer of dark particles from the foam to the molten metal suggests a process of local melting of the inserts and the consequent metallurgical bonding between the structures. This phenomenon is favored by the limited presence of surface oxides on the outer skin and on the cell walls of the foams which often can reduce foam reactivity with the molten metal and acts as obstacle in metallurgical bonding as reported in $[6,23,31]$ and previously observed by the authors using HMF foams as cores [22,23].

\section{Conclusions}

Cymat-type Al-based foams were used as permanent cores in gravity casting experiments with Al-Si-Cu-Mg alloy (EN AB-46400).

Foam inserts with a thin outer skin only on two external surfaces and three different porosities were considered. Except for the highest porosity (big pores and very low density), a certain preservation of the initial porosity (at about $50 \%$ ) was obtained after insertion of these foams as cores in cast objects. On the other hand, foams used in the previous works with a thick outer skin completely avoided infiltration. A different preparation of the foam inserts, with the possibility to have a thin outer skin also on the surface exposed to the molten metal flow can be explored in future works to improve both infiltration resistance ability and core shell bonding.

An effective metallurgical bonding was observed in some areas of the core shell interface. It can be attributed to the limited presence of surface oxides/carbonates which guarantees a higher surface reactivity of the foam core with the molten metal, differently from foams with thick outer skin which presented high surface oxidation and absence of bonding. Moreover, partial melting of the foam surface can be supposed. From this standpoint, Cymat type foams present a more favorable behavior for insertion as permanent cores in casting.

The foam ability to absorb mechanical energy, widely known in the literature and here confirmed by compression tests on the foam cores, make these experiments significant for further developments and practical applications, for example in the automotive industry, as evidenced in the introduction.

Author Contributions: Conceptualization, S.F., A.B. and G.U.; methodology, S.F., A.B., A.S., R.M. and G.U.; investigation, S.F. and A.S.; resources, G.U.; data curation, S.F., A.B., A.S. and G.U.; writingoriginal draft preparation, S.F. and G.U.; writing-review and editing, S.F., A.B., A.S., R.M. and G.U.; supervision, G.U.; project administration, G.U.; funding acquisition, G.U. and A.B. All authors have read and agreed to the published version of the manuscript.

Funding: This research was funded by DACA-I and Regione Piemonte through ICARO project (ICARO-Industrialization of Cast Aluminum pROduct, call "Competitività regionale e occupazione" F.E.S.R. 2014/2020 Obiettivo tematico OT 1-Asse I-Azione I.1b.1.1 “IR2").

Data Availability Statement: We do not have other public data to link.

Conflicts of Interest: The authors declare no conflict of interest. 


\section{References}

1. Jayasheela, P.; Patra, S.; Alvarez, R. Method to Evaluate the Acoustic Performance of the Pillar Filler Foam in a Truck Cab. In $S A E$ Technical Paper 2020-01-0505; SAE International: Warrendale, PA, USA, 2020. [CrossRef]

2. Koya, E.; Fukuda, Y.; Kitagawa, S.; Murakami, M.; Kawauchi, A.; Furue, S. Manufacturing Technology for Hollow Structure Large Aluminum Parts Production by High Pressure Die Casting (HPDC). SAE Int. J. Passeng. Cars Mech. Syst. 2015, 8, 65-72. [CrossRef]

3. Claar, T.D.; Yu, C.-J.; Hall, I.; Banhart, J.; Baumeister, J.; Seeliger, W. Ultra-Lightweight Aluminum Foam Materials for Automotive Applications. In SAE Technical Papers Series 2000-01-0335; SAE International: Warrendale, PA, USA, 2000.

4. Eifert, H.; Yu, C.-J.; Banhart, J.; Baumeister, J.; Seeliger, W. Weight Savings by Aluminum Metal Foams: Production, Properties and Applications in Automotive. In SAE Technical Papers Series 1999-01-0887; SAE International: Warrendale, PA, USA, 1999.

5. Simancik, F.; Rajner, W.; Laag, R. Alulight-Aluminum Foam for Lightweight Construction. In SAE Technical Papers Series 2000-01-0337; SAE International: Warrendale, PA, USA, 2000.

6. Ubertalli, G.; Ferraris, S. Al-Based Metal Foams (AMF) as Permanent Cores in Casting: State-of-the-Art and Future Perspec-tives. Metals 2020, 10, 1592. [CrossRef]

7. Simancik, F.; Schoerghuber, F. Complex foamed aluminum parts as permanent cores in aluminum castings. Mat. Res. Soc. Sym. Proc. 1998, 521, 151-157. [CrossRef]

8. Cingi, C.; Niini, E.; Orkas, J. Foamed aluminum parts by investment casting. Colloids Surf. A Physicochem. Eng. Asp. 2009, 344, 113-117. [CrossRef]

9. Vicario, I.; Crespo, I.; Plaza, L.M.; Caballero, P.; Idoiaga, I.K. Aluminium foam and magnesium compound casting produced by high pressure die casting. Metals 2016, 6, 24. [CrossRef]

10. Babcsan, J.; Essel, S.; Karni, N.; Szamel, G.; Beke, S.; Babcsan, N. Micro-CT measurements of die-cast car parts with aluminum foam core. Resolut. Discov. 2017, 2, 5-8. [CrossRef]

11. Domrong, C.; Srimanosaowapack, S. Production of aluminium casting with open-cell aluminium foam core. J. Chem. Eng. Mater. Sci. 2017, 8, 37-45.

12. Dobesberger, F.; Flankl, H.; Leitlmeier, D.; Birgmann, A. Lightweight Part, As Well as a Process and Device for Its Production. Patent US 2006/0029826A1, 9 February 2006.

13. Knott, W.; Niedermann, B.; Recksik, M.; Weier, A. Process for Producing Metal/Metal Foam Composite Components. Patent US 6874562B2, 3 January 2005.

14. Knott, W.; Niedermann, B.; Recksik, M.; Weier, A. Process for Producing Shaped Metal Parts. Patent US 6854506B2, 15 February 2005.

15. Singer, R.F.; Heinrich, F.; Korner, C.; Grotzschel, G. Method for Producing A Composite Structure with A Foamed Metal Core. Patent US 6675864B2, 2004.

16. ASTM. ASTM C365/C365M-16 Standard Test Methodsf Flatwise Compressive Properties of Sandwich Cores; ASTM: West Conshohocken, PA, USA, 2016.

17. Andreews, E.; Sanders, W.; Gibson, L.J. Compressive and tensile behavior of aluminum foams. Mat. Sci. Eng. A 1999, 270, 113-124. [CrossRef]

18. Dannemann, K.A.; Lankford, J. High strain rate compression of closed-cell aluminium foams. Mat. Sci. Eng. A 2000, 293, 157-164. [CrossRef]

19. Hajjari, E.; Divandari, M. An Investigation on the microstructure and tensile properties of direct squeeze cast and gravity die cast 2024 wrought Al alloy. Mater. Des. 2008, 29, 1685-1689. [CrossRef]

20. Zhang, L.Y.; Jiang, Y.H.; Ma, Z.; Shan, S.F.; Jia, Y.Z.; Fan, C.Z.; Wang, W.K. Effect of cooling rate on solidified microstructure and mechanical properties of aluminium-A356 alloy. J. Mater. Process. Technol. 2008, 207, 107-111. [CrossRef]

21. Birol, Y. Impact of grain size on mechanical properties of AlSi7Mg0.3 alloy. Mat. Sci. Eng. A 2013, 559, 394-400. [CrossRef]

22. Ferraris, S.; Ubertalli, G.; Santostefano, A.; Barbato, A. Aluminum Foams as Permanent Cores in Casting. Mater. Proc. 2021, 3, 3. [CrossRef]

23. Ferraris, S.; Santostefano, A.; Campagnoli, E.; Matteis, P.; Barbato, A.; Molina, R.; Ubertalli, G. Co-casting of Al and Al-foams. Adv. Eng. Mater. 2021. submitted.

24. Korner, C.; Singer, R.F. Processing of Metal Foams-Challenges and Opportunities. Adv. Eng. Mat. 2006, 2, 159-165. [CrossRef]

25. Banhart, J. Aluminum Foams: On the Road to Real Applications. MRS Bull. 2003, 28, 290-295. [CrossRef]

26. Korner, C.; Singer, R.F. Foaming Processes for Al in HP Degischer. In Handbook of Cellular Metals: Production Processing and Applications; Kriszt, B., Ed.; Wiley-WHC: Hoboken, NJ, USA, 2002.

27. Guner, A.; Arikan, M.M.; Nebioğlu, M. New Approaches to Aluminum Integral Foam Production with Casting Methods. Metals 2015, 5, 1553-1565. [CrossRef]

28. Commercial Applications of Cymat Metal Foams. Available online: www.cymat.com (accessed on 24 July 2019).

29. Ashby, M.F.; Evans, A.G.; Fleck, N.A.; Gibson, L.J.; Hutchinson, J.W.; Wadley, H.N.G. Metal Foams: A Design Guide; ButterworthHeinemann: Oxford, UK, 2000.

30. Pippan, R. Materials Properties. In Handbook of Cellular Metals: Production Processing and Applications; Degischer, H.P., Kriszt, B., Eds.; Wiley-WHC: Hoboken, NJ, USA, 2002.

31. Ferraris, S.; Perero, S.; Ubertalli, G. Surface Activation and Characterization of Aluminum Alloys for Brazing Optimization. Coatings 2019, 9, 459. [CrossRef] 